\title{
A Study on the Response of the Hydrodynamic Environment to the Morphology of Radial Sand Ridges in the Coastal Waters of Jiangsu
}

\author{
Changjun Qi ${ }^{1,2, *}$, Lejun Ma ${ }^{1,3}{ }^{1}$, Qinggai Wang ${ }^{2}$, Yuan Zhai ${ }^{4}$, Jixuan $\mathrm{Li}^{5}$ and Hanwen Zhang ${ }^{6}$ \\ 1 Department of Hydrology and Water Resources, Hohai University, Nanjing 210098, China; \\ rivermale@foxmail.com \\ 2 Appraisal Center for Environment and Engineering, The Ministry of Ecology and Environment of China, \\ Beijing 100012, China; wangqg@acee.org.cn \\ 3 Nanjing Hohai Technology Company, Hohai University, Nanjing 210098, China \\ 4 Water Resource and Hydropower Planning and Design General Institute, Beijing 100120, China; \\ zhaiyuan@giwp.org.cn \\ 5 Wuchuan Water Environment Company, Shanghai 200235, China; li.jixuan@163.com \\ 6 Shanghai Investigation, Design \& Research Institute Co., Ltd., Shanghai 200335, China; \\ hanwenzhan05015134@163.com \\ * Correspondence: qcj882@hhu.edu.cn; Tel.: +86-25-6815-6577
}

Received: 21 August 2019; Accepted: 16 October 2019; Published: 21 October 2019 updates

\begin{abstract}
A two-dimensional hydrodynamic model for the waters off the coast of Jiangsu, where there are radial sand ridges (RSRs) (hereinafter, the RSR area), was established based on measured topographic, tide level and tidal current data. Considering the complex topographic and geomorphic characteristics of the RSR group in this area, an unstructured grid was used for the calculation. A four-layer refinement was applied to the grid from outside to inside to better fit the complex topography. The simulations were performed to examine the response of the hydrodynamic environment to the morphology of the RSRs in three scenarios, namely, when there are natural RSRs, no RSRs, and partially reclaimed RSRs. When there are no or partially reclaimed RSRs, the tidal current field still exists in a radial pattern in the RSR area. The radial tidal current field is relatively stable and is not controlled by the morphologies of the RSRs. The topographic changes do not alter the distribution pattern of the radial tidal current field but do affect the local current fields. When there are no RSRs, the flood currents can directly reach Jianggang. Under practical conditions, the RSRs block the tidal currents during a flood tide to some extent. This phenomenon is particularly pronounced when the RSRs are partially reclaimed. For example, during an ebb tide, when the tidal currents encounter sand ridges or reclamation areas, their streamlines bend, and they flow around the obstacles. This change will affect the material transport, sediment deposition and seabed erosion.
\end{abstract}

Keywords: RSRs; hydrodynamic model; numerical simulation; Jiangsu

\section{Introduction}

With a distinct morphology, the radial sand ridges (RSRs) in the coastal waters of Jiangsu encompass a large area and form an area (hereinafter, RSR area) with dynamic sedimentary geomorphic features that is unique in China and rare worldwide. Investigating and studying this area is of great importance to theoretical research on marine sedimentary dynamics and the ecological protection of offshore wetlands and tidal flats in Jiangsu. In recent years, researchers in China have offered many new views on the hydrodynamic conditions around the RSRs, as well as their evolution, by extensively analysing marine hydrological, hydrodynamic, sediment survey and satellite remote sensing data. 


\subsection{Cause of RSR Formation}

RSRs, which are tidal (sand) ridges with unique submarine landforms, consist of a series of sand bodies that are parallel to the tidal currents and sand channels between them [1]. This unique submarine landform is formed by strong tidal currents. Rectilinear tidal currents are essential for the formation and development of tidal sand ridges. A tidal current velocity of $0.5-2.5 \mathrm{~m} / \mathrm{s}$ is favourable for the development of tidal sand ridges [2]. Some researchers noted that underwater sand ridges are formed by directional, strong tidal or storm currents $[3,4]$. On this basis, underwater sand ridges can be categorized into two types, namely, tidal current ridges and storm current ridges. The research on the formation conditions for underwater sand ridges in China has found that underwater sand ridges can be formed by directional currents that flow at 0.5 to $1.8 \mathrm{~m} / \mathrm{s}$, particularly 1.0 to $1.5 \mathrm{~m} / \mathrm{s}$. Tidal current ridges are often distributed in shallow sea and coastal areas with water depths of less than $35 \mathrm{~m}$, such as estuaries, bays and the mouths of straits [5,6]. In the RSR area off the coast of Jiangsu, the tidal currents flow at 1.0 to $1.5 \mathrm{~m} / \mathrm{s}$ and there are also large amounts of loose sediment, thereby providing conditions for the formation and development of tidal current ridges. The numerical simulations of the tidal currents in the RSR area have shown that the radial tidal current field exists independent of the submarine topography and may be the main driving force that forms and shapes RSRs [7]. Tidal currents are the main driving force that forms and maintains the RSR group. Standing tidal waves, a large tidal range and a radial tidal current field in the RSR area give rise to the planar radial distribution pattern and the "wide tidal flats, deep channels" structural morphology section of the RSR group [8]. Tidal currents are the main dynamic factor that leads to the formation and development of RSRs in the southern Yellow Sea. The differences in the tidal energy efficiency and tidal current velocity distribution result in the spatial distribution and morphology of southern and northern sand ridges and deep channels in the RSR area $[9,10]$. Abundant sediment and a unique long-term stable radial tidal current field are necessary and sufficient conditions for the formation and development of an RSR group in the southern Yellow Sea [11]. The RSR group is an accumulation landform formed under the action of tides and tidal currents [12]. As sand ridges gradually migrate south-westward, new sand ridges are continually replacing the old ones. These sand ridges should be called quasi-active sand ridges instead of dying or residual sand ridges [13].

\subsection{Formation Time of Radiation Sandbanks}

Regarding the age of radiation sandbar formation, various studies have differing opinions. Yang Chang believed that the radiant sand ridge group is a Holocene sediment, which formed approximately 10,000 years ago [14]. Zhang believed that the earliest formation of the Yellow Sea shelf sand ridge was 4000 years ago and the modern tidal sand ridge was formed in 2000 [15]. Zhu et al. believed that the largest transgression of the Holocene occurred 3800 years ago in the embryonic development stage of the radiated sandbar [16].

\subsection{Relationship between RSRs and the Radial Tidal Current Field}

There are two completely opposite views on the relationship between RSRs and the radial tidal current field. One view states that the radial tidal current field shapes the RSRs. Under the hydrodynamic action of coastal currents, gradient currents are formed at Jinggong and radiate towards the open sea, forming RSRs [17]. The other view is that the radial topography existed first and that radial tidal currents were formed later and that the radial topography determines the radial tidal currents. The RSRs were formed off the coast of Jianggang with the subaqueous delta of the paleo-Yangtze River as the initial morphology, with the thick sediment of the subaqueous delta of the paleo-Yangtze River as the material source and subsequently forming a radial tidal current field [18-20]. 


\subsection{Hydrodynamic Characteristics of the RSRs}

Numerous researchers in China and elsewhere have conducted surveys and simulations of the hydrodynamic environment surrounding the RSRs off the coast of Jiangsu. The coastal waters of Jiangsu are mainly controlled by two tidal wave systems. A sinistral rotary tidal wave system with an amphidromic point (near $32^{\circ} 30^{\prime} \mathrm{N}, 121^{\circ} 10^{\prime} \mathrm{E}$ ) in the southern Yellow Sea controls the northern coastal waters of Jiangsu, whereas a progressive tidal wave system that originates in the East China Sea controls the southern coastal waters. The two systems converge at Jianggang. Regular semidiurnal tides and strong semidiurnal tidal currents are the main types of tides and currents in the RSR area, respectively, and the tidal currents in this area converge and diverge approximately at Jianggang in a radial fashion [21]. Due to the convergence of tidal waves and concentrated wave energy, a large tidal range and strong tidal currents are present in the RSR area, which is a strong tide area. The maximum measured tidal range in the RSR area is $9.28 \mathrm{~m}$. Under the combined action of the tidal wave systems and tidal inlets, the strength of the flood tide is generally higher than that of the ebb tide (spring tides). For example, the flood and ebb currents flow at 1.9 and $1.8 \mathrm{~m} / \mathrm{s}$, respectively, off the coast of Wanggang and the flood and ebb currents flow at 2.0 and $1.75 \mathrm{~m} / \mathrm{s}$, respectively, in the Xiaomiaohong Waterway in Lusi [22]. Thus, the complex tidal wave systems and the unique RSR group landform off the coast of Jiangsu increase the distinctiveness and diversity of the hydrodynamic environment in the area.

\subsection{Development and Use of the RSRs}

Coastal tidal flats are important and precious resources. Before the implementation of any development and use activity, the effects of engineering construction on tidal flats should be examined from a scientific perspective and appropriate protection measures should be presented. Large-scale, rapid human activity, such as tidal flat reclamation, will have a profound impact on the coastal environment, and the topography and dynamic environment of the waters will reach a new equilibrium through the interaction after the implementation of reclamation [23]. Therefore, the latest research results show that high-precision mathematical tidal current models suitable for the coastal waters of Jiangsu with unique topographic and geomorphic features should be established based on reclamation projects to investigate the internal link between the hydrodynamic environment and the cause of the formation of the RSR group. Additionally, some researchers analysed the effects of the construction of artificial islands in the RSR area off the coast of Rudong on the tidal current field off the coast of Jiangsu and on the tidal volume in each waterway, as well as the surrounding hydrodynamics and sediment erosion and deposition [24-26]. Additionally, a two-dimensional (2D) mathematical tidal current model was established for the RSR area off the coast of Jiangsu and it was used to analyse the effects of a wind power farm in the intertidal zone on marine hydrodynamics [27,28]. Large-scale human activity and the geomorphic features of the RSRs lead to an increase in the complexity of the hydrodynamic environment in this area. Therefore, an ongoing, in-depth investigation of the response of the hydrodynamic environment to morphological changes in the RSRs is essential.

In this study, a 2D hydrodynamic model was established for the RSR area off the coast of Jiangsu based on the measured topographic, tide level and tidal current data. Numerical simulations were performed to examine the hydrodynamic environment in the RSR area off the coast of Jiangsu and to analyse the response of the hydrodynamic environment to the morphology of RSRs in three scenarios, namely, when there are natural RSRs, no RSRs and partially reclaimed RSRs.

\section{Study Area}

An area of the coastal waters of Jiangsu where an RSR group exists was selected as the study area (Figure 1a). The RSR group, stretching $200 \mathrm{~km}$ from south to north and $90 \mathrm{~km}$ from east to west, consists of over 10 large banded sand ridges that converge approximately at Jianggang and extend northward, eastward and south-eastward. Approximately 70 sand ridges of varying sizes are exposed in the coastal waters during a low tide, and sand ridges above sea level $(0 \mathrm{~m})$ encompass an area of 
$2100 \mathrm{~km}^{2}$. The tidal inlets are distributed between the sand ridges with water depths ranging from approximately 0 to $25 \mathrm{~m}$.

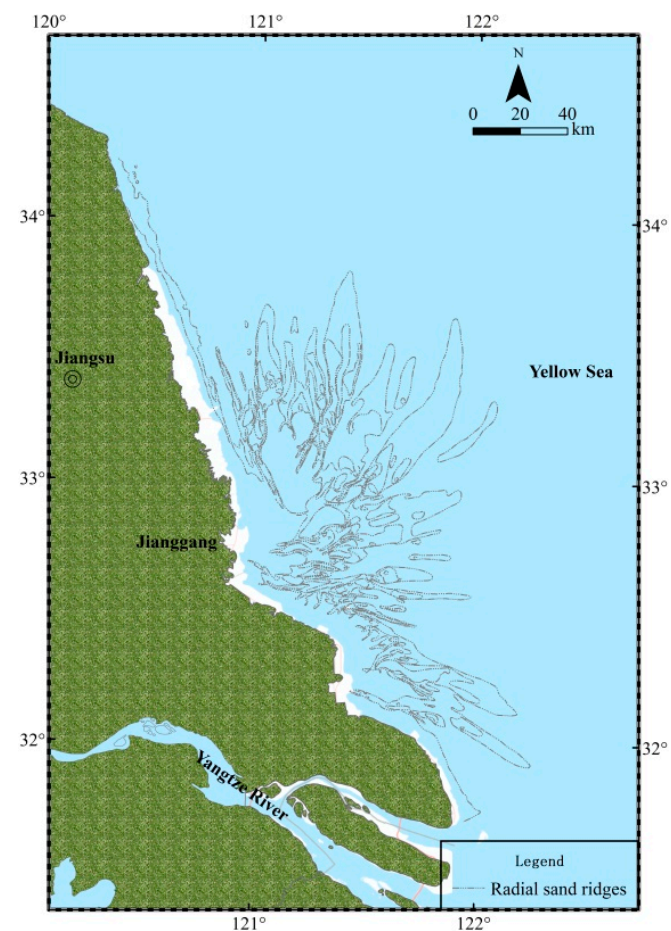

(a)

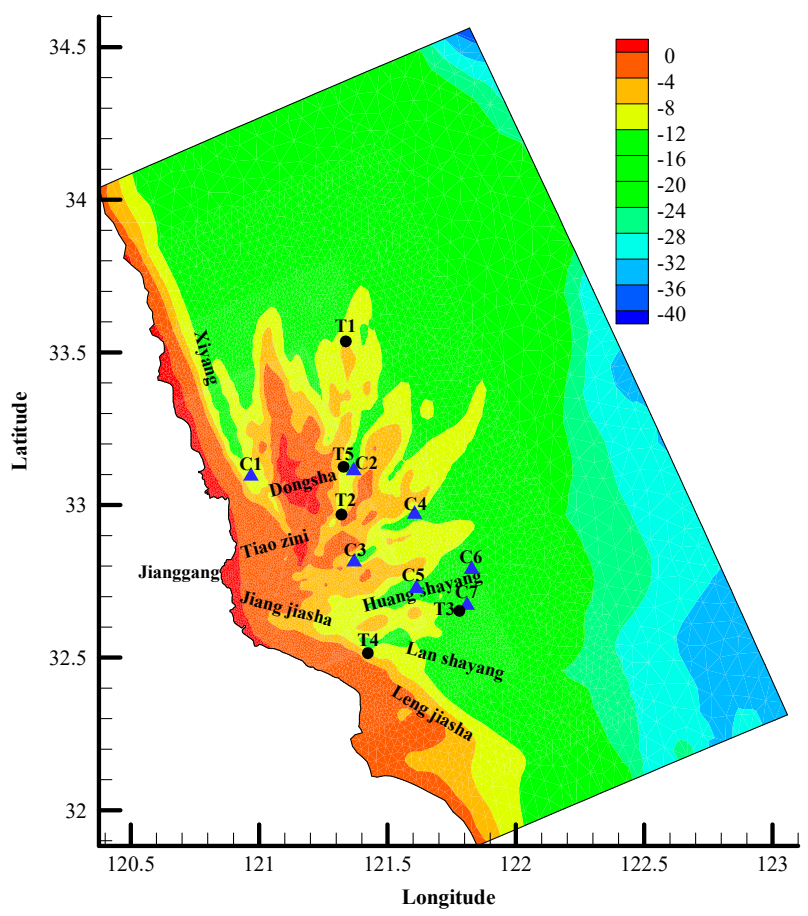

(b)

Figure 1. (a) The area of the coastal waters of Jiangsu; (b) The bathymetry and observation points signify the tide level observation points; $\boldsymbol{\Lambda}$ signify the tidal current observation points).

As shown in Figure $1 \mathrm{~b}$, the study area has a unique geomorphology and a complex topography $[29,30]$. Among the radiant sandbars, there are more than a dozen large sandbars. Most of the sandbars are linear. Most of the sandbank heights are above the theoretical low tide surface and they are exposed when the tides fall. The exposed areas of the larger sandbars, such as Dongsha, Tiaozini, Jiangiiasha and Lengjiasha, are $693.79 \mathrm{~km}^{2}, 505 \mathrm{~km}^{2}, 124.65 \mathrm{~km}^{2}$ and $107.28 \mathrm{~km}^{2}$, respectively.

Among the radiant sandbars, there are deep-water tidal inlets, such as Xiyang, Huangshayang, and Lanshayang. The Xiyang tidal inlet is the most important tidal channel in the northern part of the tidal flat and it is basically north-south. The Huangshayang and Lanshayang tidal inlets are located in the south-central part of the radiant sandbar and are basically east-west. The $-20 \mathrm{~m}$ isobath of the Xiyang tidal inlet is $2.5 \mathrm{~km}$ wide and $10 \mathrm{~km}$ long; the $-20 \mathrm{~m}$ isobath of the Huangshayang tidal inlet is $0.6 \mathrm{~km}$ wide and $4 \mathrm{~km}$ long; the $-20 \mathrm{~m}$ isobath of the Lanshayang tidal inlet is $1.3 \mathrm{~km}$ wide and $13 \mathrm{~km}$ long.

\section{Research Methods}

\subsection{Mathematical Model}

The coastal waters of Jiangsu are wide and shallow. A 2D semi-implicit shallow-water model was selected and solved using the finite volume method [31-34]. Considering the complex topographic and geomorphic features of the RSR group in these waters, an unstructured grid was used for the calculation to fit the complex topography.

The basic governing equations for calculating tidal currents are as follows:

$$
\frac{\partial \eta}{\partial t}+\frac{\partial H u}{\partial x}+\frac{\partial H v}{\partial y}=0
$$




$$
\begin{aligned}
& \frac{\partial u}{\partial t}+u \frac{\partial u}{\partial x}+v \frac{\partial u}{\partial y}+g \frac{\partial \eta}{\partial x}-f v+g \frac{u \sqrt{u^{2}+v^{2}}}{C^{2} H}=0 \\
& \frac{\partial v}{\partial t}+u \frac{\partial v}{\partial x}+v \frac{\partial v}{\partial y}+g \frac{\partial \eta}{\partial y}+f u+g \frac{v \sqrt{u^{2}+v^{2}}}{C^{2} H}=0
\end{aligned}
$$

where $H=h+\eta$ is the total water depth; $h$ is the distance between the seabed and the still sea surface; $\eta$ is the sea surface fluctuation above the still sea surface; $u$ and $v$ are the velocity components in the $x$ and $y$ coordinate directions; $f=2 \omega \sin \varphi$ is the Coriolis force coefficient ( $\omega$ is the angular velocity of the earth and $\varphi$ is the geographic latitude); $C=M \times h^{1 / 6}$ is the Chezy coefficient ( $M$ is the Manning coefficient); $t$ is time and $g$ is the gravitational acceleration.

\subsection{Grid and Bathymetry}

\subsubsection{Grid}

To prevent the overflow of dry points at the boundaries of the model and improve its stability, the model was set to include the RSRs off the eastern coast of Jiangsu based on the topographic characteristics of the study area. The coastline length of the study area is approximately $340 \mathrm{~km}$. The computational domain stretches approximately $270 \mathrm{~km}$ from south to north and approximately $160 \mathrm{~km}$ from east to west and encompasses an area of approximately $43,200 \mathrm{~km}^{2}$.

Instead of simply refining the mesh according to depth gradient, (which is a common strategy that generates a large number of elements), the computation domain was divided into several zones from offshore to nearshore. As shown in Figure 2, each zone has its own mesh parameters, such as the maximum element size, the larger element offshore or the smaller nearshore.

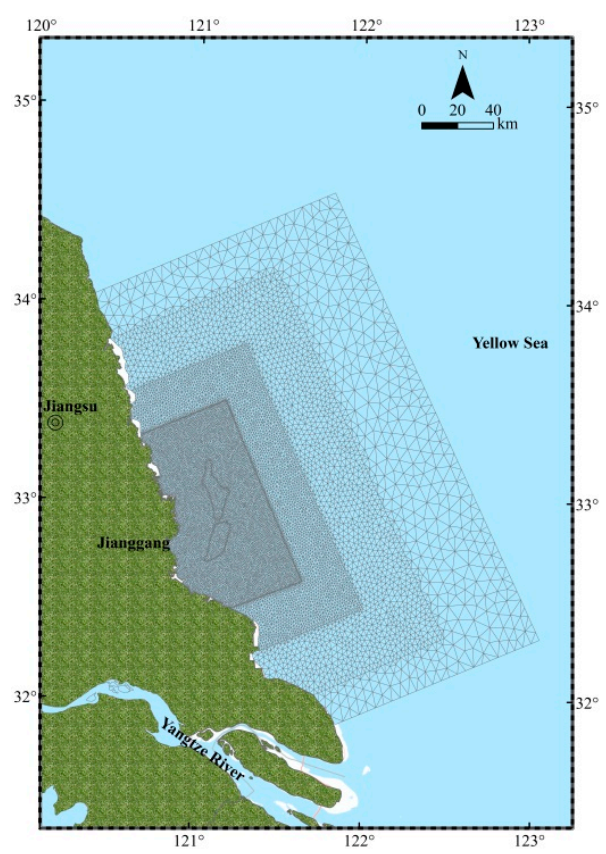

Figure 2. Grid generation of the study area.

\subsubsection{Bathymetry}

The model bathymetry has several sources. For the offshore part, the sea chart was chosen. This is measured by the Chinese navy. For the sandy ridge part, the digital format bathymetry from several offshore wind farm projects was obtained. The topography of the study area is shown in Figure $1 \mathrm{~b}$.

When simulating the hydrodynamics in an area with alternating sand ridges and deep channels similar to the study area, the grid should be refined as much as possible based on the topographic conditions. Good model validation results can be obtained by fine control of the grid scale. 


\subsection{Boundaries and Initial Conditions}

\subsubsection{Open Boundaries}

The west boundary of the 2D hydrodynamic model is the shore boundary, and its north, east and south boundaries are open boundaries. When computing tidal currents, a given tide level process at the open boundaries is needed. The tidal current field within the computational domain is jointly controlled by the rotary tidal wave system in the southern Yellow Sea and the progressive tidal wave system originating in the East China Sea. To ensure that the tidal current field within the computational domain can reflect the actual tidal current movement, an open sea tide level process was generated for the open boundaries of the model based on the harmonic constant provided by the MIKE 21 Global Tide Model.

Regarding the offshore water level boundary conditions, two points were selected and the tidal constituents were extracted from the MIKE 21 Global Tide Model. For the north and south boundaries, the water levels predicted based on 8 tidal constituents were usemad as the $\mathrm{N}$ and $\mathrm{S}$ boundary water levels, respectively. While for the east boundary, linear interpolation was carried out for generating the water level based on the N/S boundary. The positions and 8 tidal constituents are listed in the Table 1.

Table 1. The positions and 8 tidal constituents.

\begin{tabular}{ccccc}
\hline \multirow{2}{*}{ Tidal Constituent } & \multicolumn{2}{c}{ Point 1 (Lon: 121.82; Lat: 34.56) } & \multicolumn{2}{c}{ Point 2 (Lon: 123.06; Lat: 32.31) } \\
\cline { 2 - 5 } & Amplitude & Phase & Amplitude & Phase \\
\hline M2 & 0.20 & 119.97 & 1.29 & 86.52 \\
S2 & 0.11 & 162.52 & 0.57 & 114.85 \\
K1 & 0.12 & 256.94 & 0.16 & 50.98 \\
O1 & 0.10 & 196.09 & 0.09 & 26.74 \\
N2 & 0.05 & 115.03 & 0.24 & 67.44 \\
P1 & 0.04 & 252.20 & 0.05 & 46.78 \\
K2 & 0.03 & 164.33 & 0.15 & 117.58 \\
Q1 & 0.02 & 162.30 & 0.01 & 51.32 \\
\hline
\end{tabular}

\subsubsection{Moving Boundaries}

The dry/wet cycling in the intertidal zone within the computational domain was treated using a frozen grid analysis. When the water depth at a designated grid point is less than $\varepsilon_{\text {dry }}$, the grid point is set as a dry point and not taken into consideration. When the water depth at a certain grid point is greater than $\varepsilon_{\text {dry }}$ but less than $\varepsilon_{\text {wet }}$, the current velocity at this grid point is set to zero and this grid point is only included when computing the continuity equation of flow. When the water depth at a certain grid point is greater than $\varepsilon_{\text {wet }}$, this grid point is included in the computation and the tidal flat at this grid point is considered to be submerged under tidewater conditions.

\subsection{Calculation Conditions}

Three topographic conditions were calculated in the hydrodynamic model, namely, natural RSRs, no RSRs and partially reclaimed RSRs. No sediment transport model was considered.

Natural RSRs - the RSRs that remain in the natural condition, as shown in Figure 1b.

No RSRs-it is assumed that the area contains no RSRs and has a flat submarine topography. The flat submarine depth is $-16 \mathrm{~m}$, as shown in Figure 3a.

Partially reclaimed RSRs - it is assumed that the RSRs have been reclaimed in two areas, i.e., A and $B$, as shown in Figure 3b. 


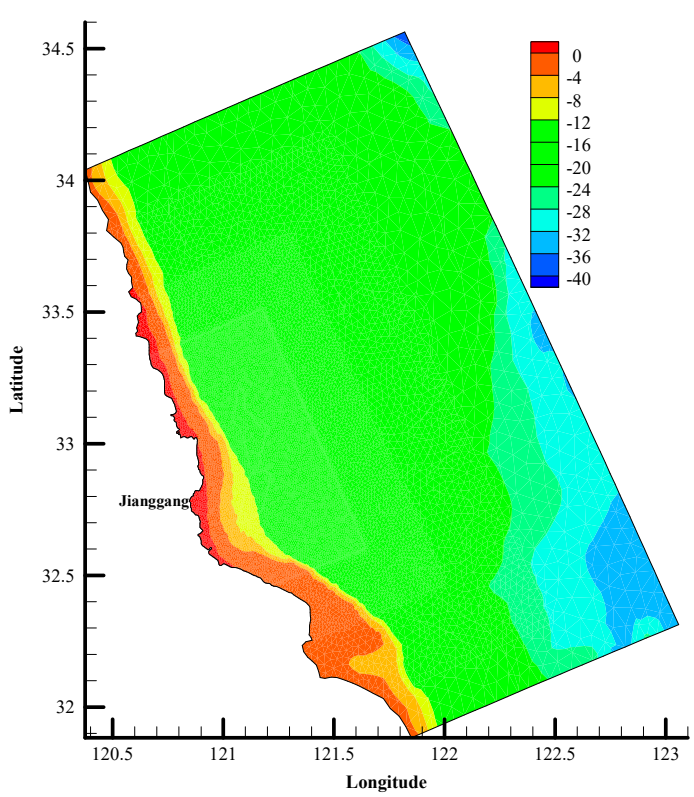

(a)

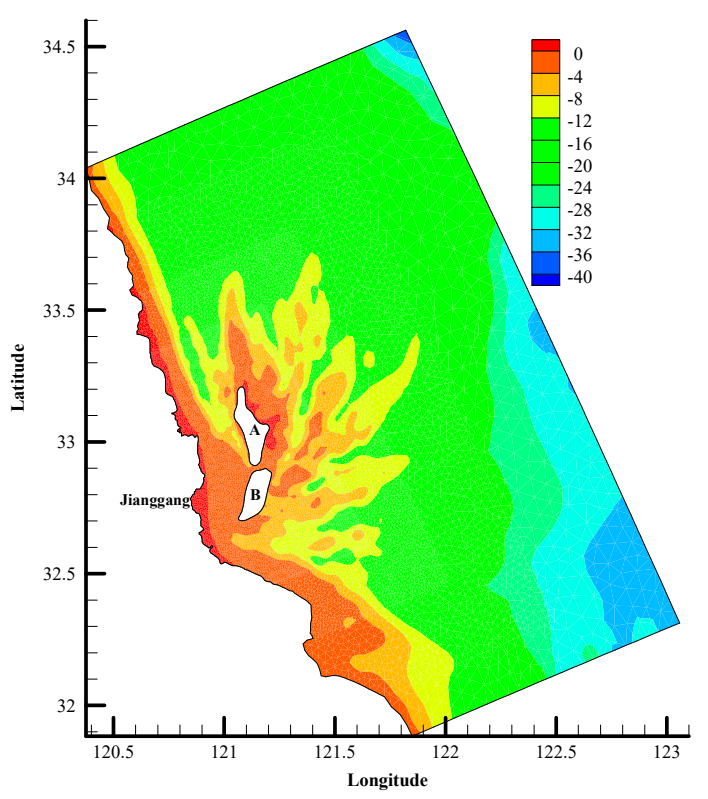

(b)

Figure 3. Assumed topographic conditions: (a) No radial sand ridges (RSRs); (b) partially reclaimed RSRs.

\section{Results}

\subsection{Model Validation}

\subsubsection{Validation Data}

The established 2D hydrodynamic model was validated using the tide level and tidal current data for the RSR area collected between 5 August and 13 August, 2010. There were 5 tide level observation points (T1-T5) and 7 tidal current observation points (C1-C7) in the RSR area. The locations of the observation points are shown in Figure 1b. The time spans of the data included spring tide, moderate tide and neap tide. The spring tide occurred between 12:00 on 12 August 2010 and 13:00 on 13 August 2010. The moderate tide occurred between 08:00 on 8 August 2010 and 09:00 on 9 August 2010. The neap tide occurred between 16:00 on 5 August 2010 and 17:00 on 6 August 2010.

\subsubsection{Validation Results}

The tide levels and tidal current velocities and directions calculated by the model were validated using the data measured at 5 tide level observation points and 7 tidal current observation points (Figures 4-6). The tide levels were observed continuously during the observation period. The tidal current velocities and directions were observed only in the spring, moderate and neap tides. The error analyses of the measured and calculated values are shown in Tables 2-4.

As shown in Figure 4, the measured values of the tidal stations are in good agreement with the calculated values, and the high tide and low tide, as well as the tidal level process, are basically consistent. As shown in Table 2, the correlation coefficients between the measured values and the calculated values of the tidal stations are $0.96,0.98,0.99,0.99$, and 0.97 , and the correlations between the measured values and the calculated values are good.

From the verification results of the tidal current velocity (Figure 5) and direction (Figure 6), it can be observed that the tidal current velocity correlation between the calculated value at point $\mathrm{C} 7$ and the measured value is slightly worse. The correlation coefficient is 0.78 and the calculated values of the flow points at the other points are generally consistent with the measured values. The tidal current direction correlation coefficients between the calculated values and the measured values of each point 
are $0.80,0.71,0.74,0.70,0.92,0.80$, and 0.89 . The simulated direction conversion process is basically consistent with the measured process.

Overall, it can be concluded that the established 2D hydrodynamic model can be used to simulate the hydrodynamic environment in the RSR area.
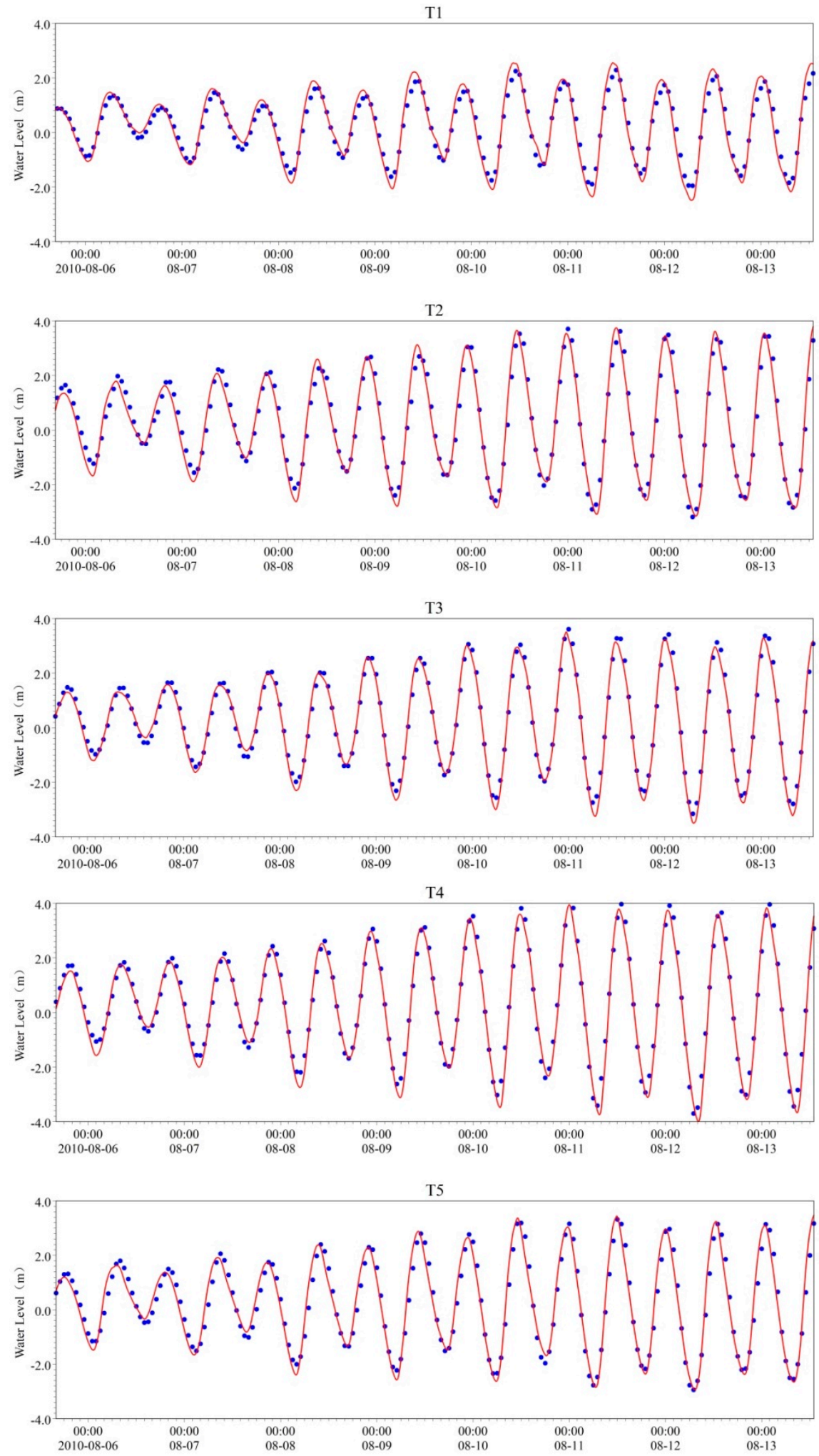

Figure 4. Tide level validation results simulated values). 

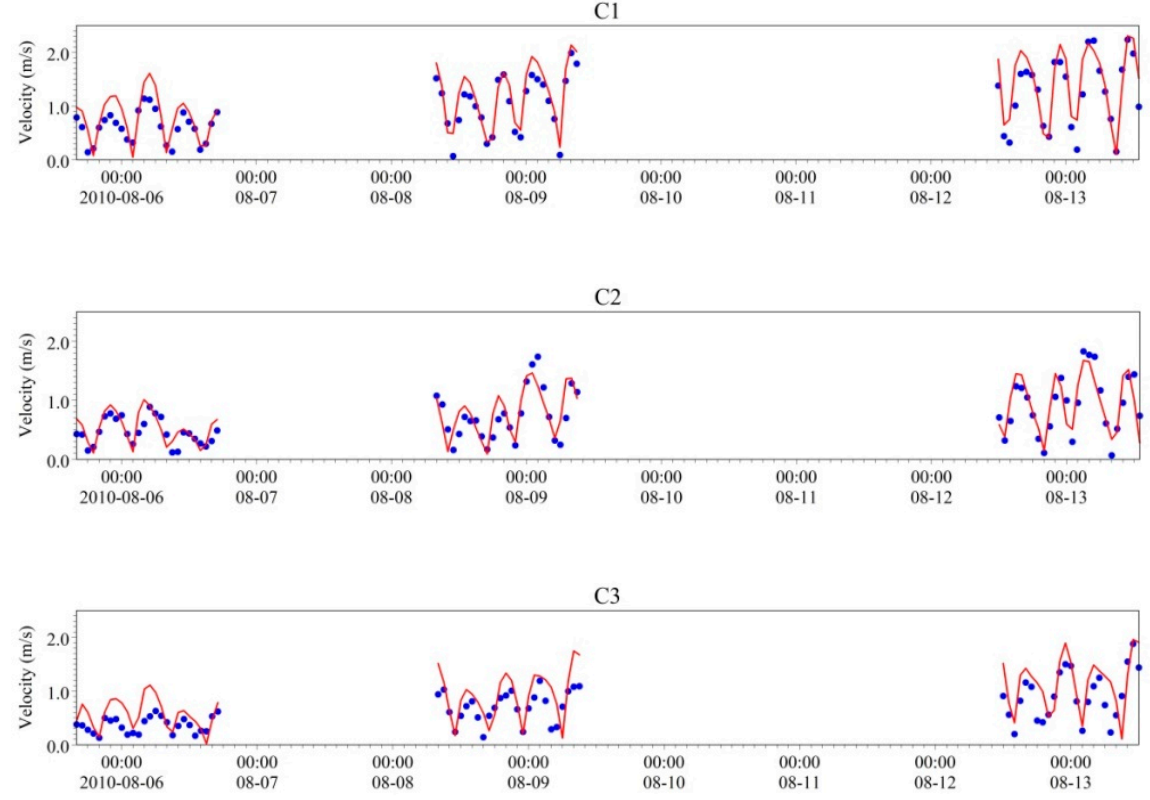

C4
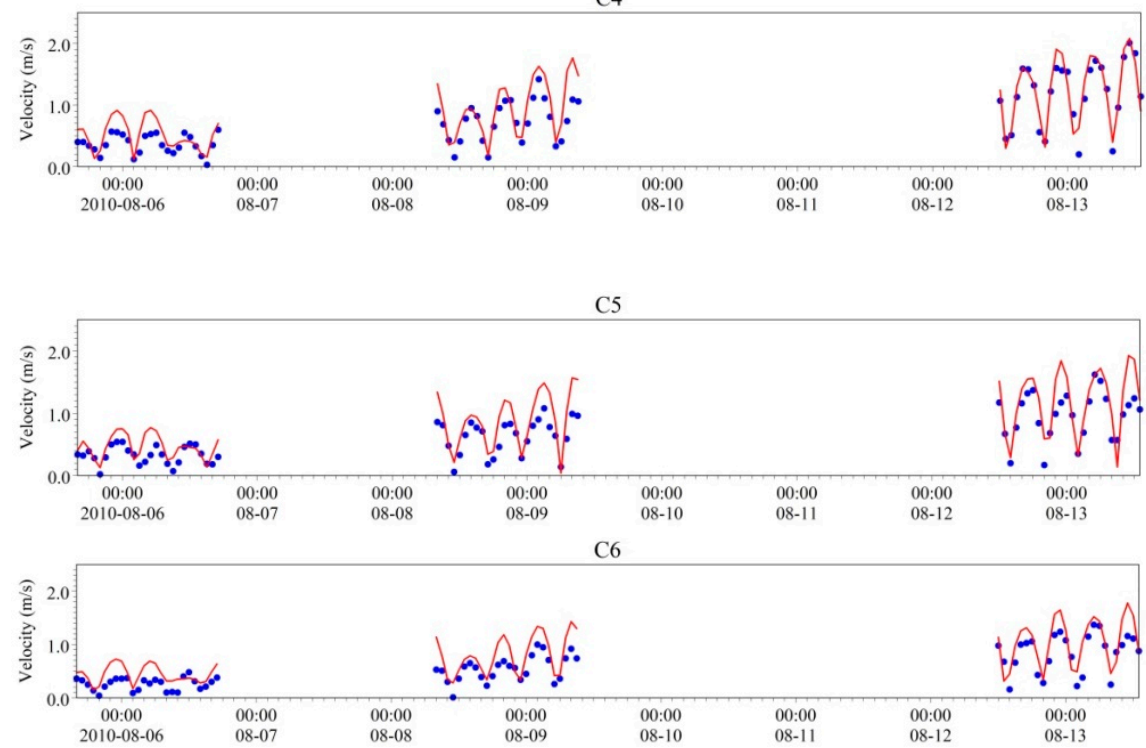

C7

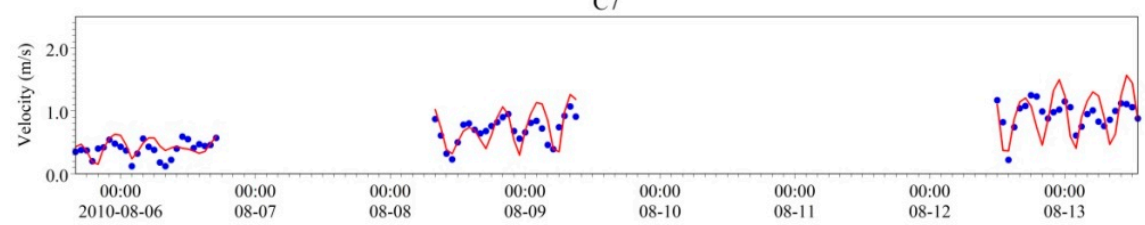

Figure 5. Tidal current velocity validation results $(\bullet \bullet$ signify the measured values; signify the simulated values). 

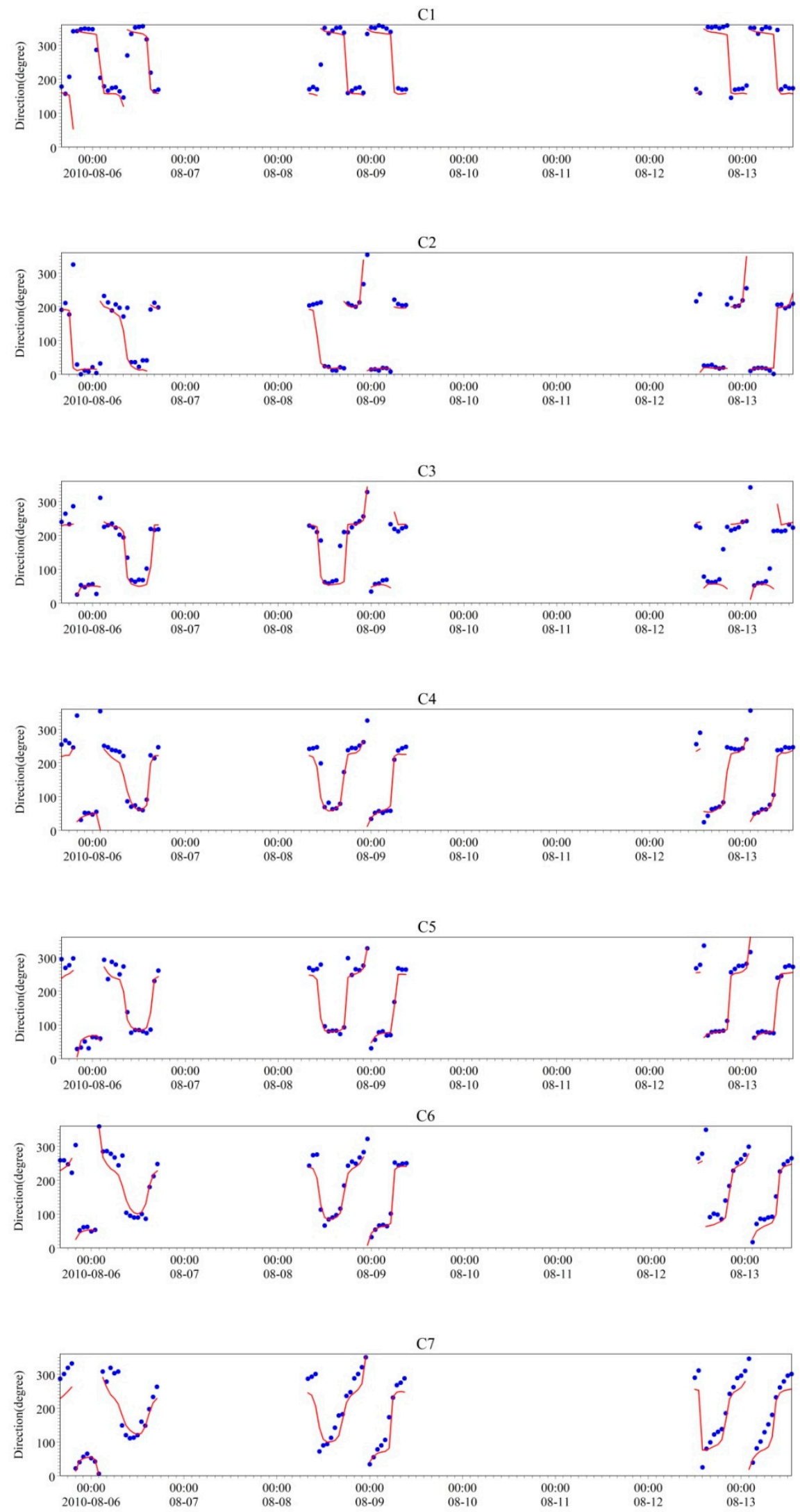

Figure 6. Tidal current direction validation results $(\bullet \bullet$ signify the measured values; signify the simulated values). 
Table 2. Tide level verification error.

\begin{tabular}{|c|c|c|c|c|c|}
\hline Verification Error & T1 & $\mathrm{T} 2$ & T3 & $\mathrm{T} 4$ & T5 \\
\hline Measured mean square error & 1.35 & 1.80 & 1.71 & 1.96 & 1.65 \\
\hline Calculated value mean square error & 1.62 & 1.84 & 1.75 & 2.01 & 1.65 \\
\hline $\begin{array}{l}\text { Measured value and calculated value } \\
\text { correlation coefficient }\end{array}$ & 0.96 & 0.98 & 0.99 & 0.99 & 0.97 \\
\hline
\end{tabular}

Table 3. Tidal current velocity verification error.

\begin{tabular}{|c|c|c|c|c|c|c|c|}
\hline Verification Error & $\mathrm{C} 1$ & $\mathrm{C} 2$ & $\mathrm{C} 3$ & $\mathrm{C} 4$ & C5 & C6 & C7 \\
\hline Measured mean square error & 0.57 & 0.44 & 0.39 & 0.50 & 0.38 & 0.35 & 0.29 \\
\hline Calculated value mean square error & 0.61 & 0.42 & 0.47 & 0.52 & 0.50 & 0.42 & 0.35 \\
\hline $\begin{array}{l}\text { Measured value and calculated value } \\
\text { correlation coefficient }\end{array}$ & 0.93 & 0.84 & 0.80 & 0.92 & 0.92 & 0.90 & 0.78 \\
\hline
\end{tabular}

Table 4. Tidal current direction verification error.

\begin{tabular}{cccccccc}
\hline Verification Error & C1 & C2 & C3 & C4 & C5 & C6 & C7 \\
\hline $\begin{array}{c}\text { Measured mean square error } \\
\text { Calculated value mean square error }\end{array}$ & 90.79 & 101.62 & 86.28 & 98.65 & 101.79 & 94.29 & 101.56 \\
$\begin{array}{c}\text { Measured value and calculated value } \\
\text { correlation coefficient }\end{array}$ & 0.80 & 0.71 & 0.74 & 0.70 & 0.92 & 0.80 & 0.89 \\
\hline
\end{tabular}

\subsection{Tidal Current Field Analysis}

\subsubsection{Tidal Current Field in the Natural RSR Area}

Figure 7 shows the maximum flood and ebb current fields under the natural RSR condition. There are regular semidiurnal tides and strong tidal currents over the entire RSR area. The areas north and south of Jianggang are mainly controlled by the rotary tidal wave system in the southern Yellow Sea and the progressive tidal wave system originating from the East China Sea, respectively. During a flood tide, the tidal currents converge from the open sea towards Jianggang. During an ebb tide, the tidal currents diverge from Jianggang towards the open sea. Rectilinear currents are the main type of current in the coastal waters and tidal inlets in the RSR area. At the nearshore of Jianggang, the current velocity is approximately $0.5-0.7 \mathrm{~m} / \mathrm{s}$. The current velocity is $1.0-2.0 \mathrm{~m} / \mathrm{s}$ over the RSR area. The maximum current velocity reaches over $2.5 \mathrm{~m} / \mathrm{s}$ in some tidal inlets (e.g., Xiyang tidal inlet).

As shown in the local tidal current field, an overbank flow occurs in the shallow-water zones of the RSR area as a result of topographic effects as the water level rises during a flood tide. During an ebb tide, the water level drops, the sand ridges on the tidal flats are exposed and the tidal currents flow into the tidal inlets. During the maximum flood period of a spring tide, the tidal current velocities are high in the east and low in the west, and the tidal currents in the eastern RSR area generally flow at a velocity greater than $1.5 \mathrm{~m} / \mathrm{s}$ and in an azimuth direction of 180-270 degrees. In comparison, the tidal current velocities in the western RSR area close to the shore are generally lower than $1.0 \mathrm{~m} / \mathrm{s}$. During the maximum ebb period of a spring tide, the tidal current velocities are higher than those during the maximum flood period. In addition, the difference in the tidal current velocity between the eastern and western RSR area decreases and ebb currents generally flow in an azimuth direction of 0-90 degrees. In the Xiyang tidal inlet in the north-western RSR area, the maximum ebb current velocity can reach $2.6 \mathrm{~m} / \mathrm{s}$ and the ebb current flows in an azimuth direction exceeding 330 degrees. High velocities are the notable characteristics of tidal currents in the RSR area. 

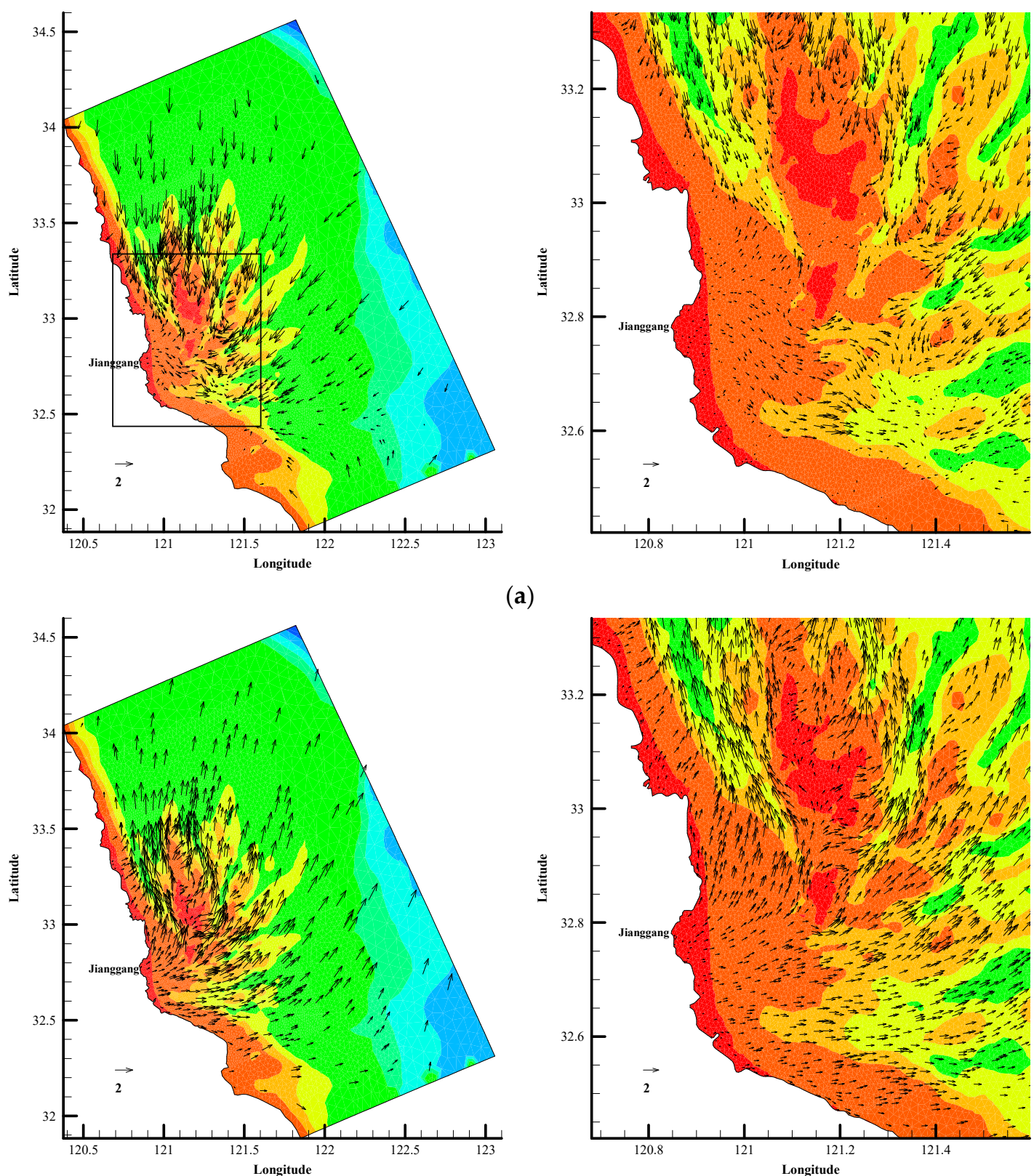

(a)

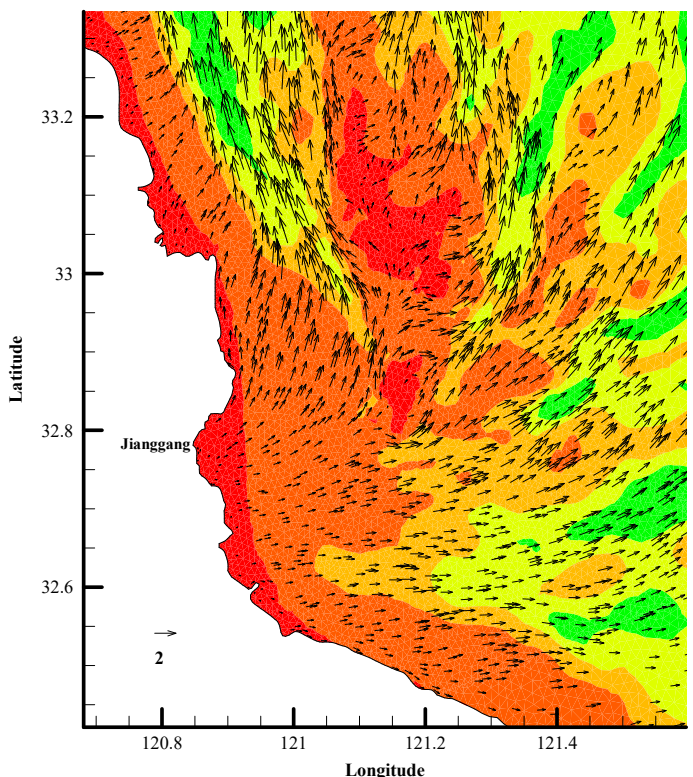

(b)

Figure 7. Maximum flood and ebb current fields when the natural RSRs are present (the base map shows the topography: left is the global tidal current field and right is the local tidal current field); (a) Maximum flood; (b) Maximum ebb.

\subsubsection{Current Field in Different Topographic Conditions}

Figure 8 shows the maximum flood and ebb current fields when there are no RSRs. Figure 9 shows the maximum flood and ebb current fields when the RSRs are partially reclaimed. Compared with the maximum flood and ebb current fields when the natural RSRs are present (Figure 7), the tidal current field still exists in a radial pattern in this area when there are no RSRs or when the RSRs are partially reclaimed. Similar to the maximum flood and ebb current fields when the natural RSRs are present, when there are no RSRs or the RSRs are partially reclaimed, tidal currents converge from the open sea towards Jianggang during a flood tide and diverge from Jianggang towards the open sea during an ebb tide. The radial tidal current field exists independent of the RSRs. 

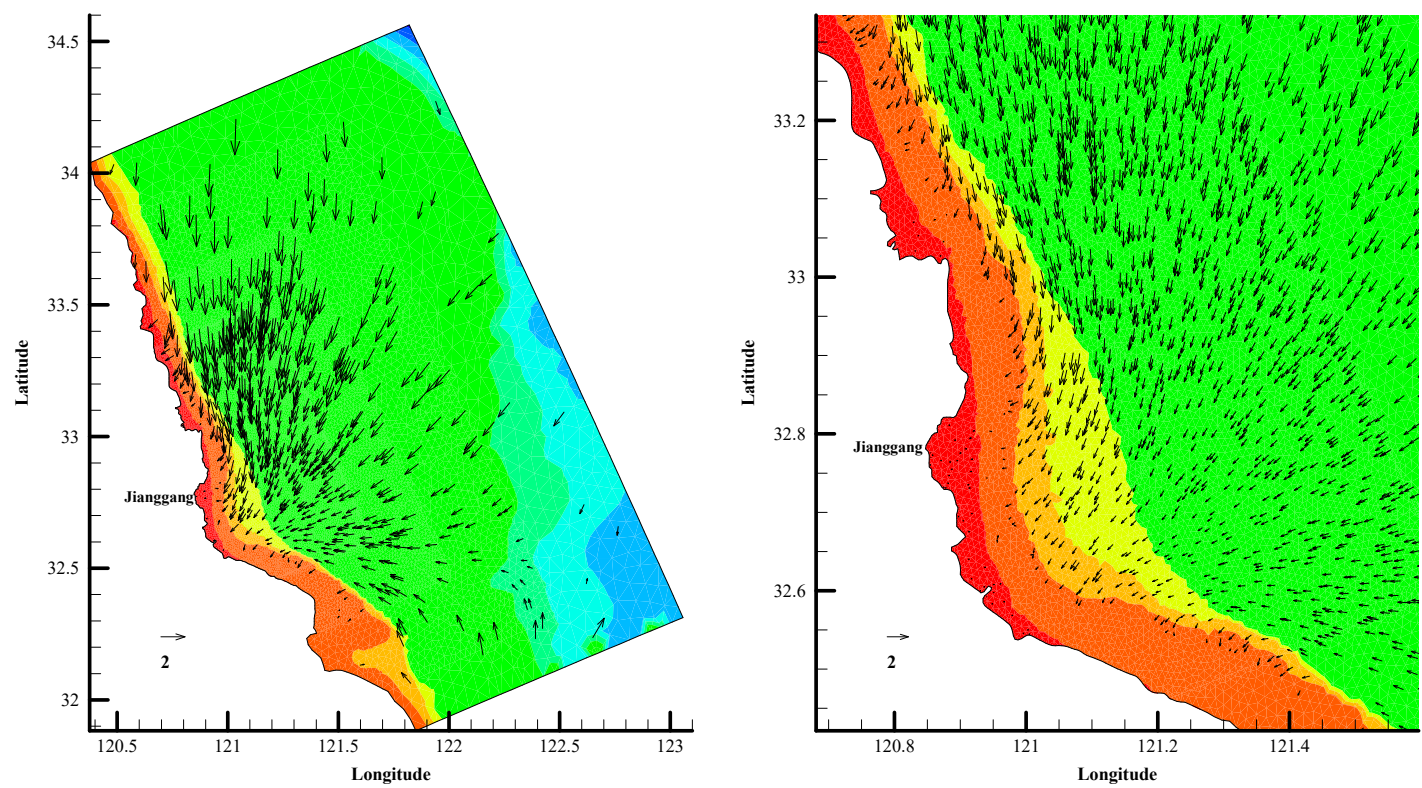

(a)
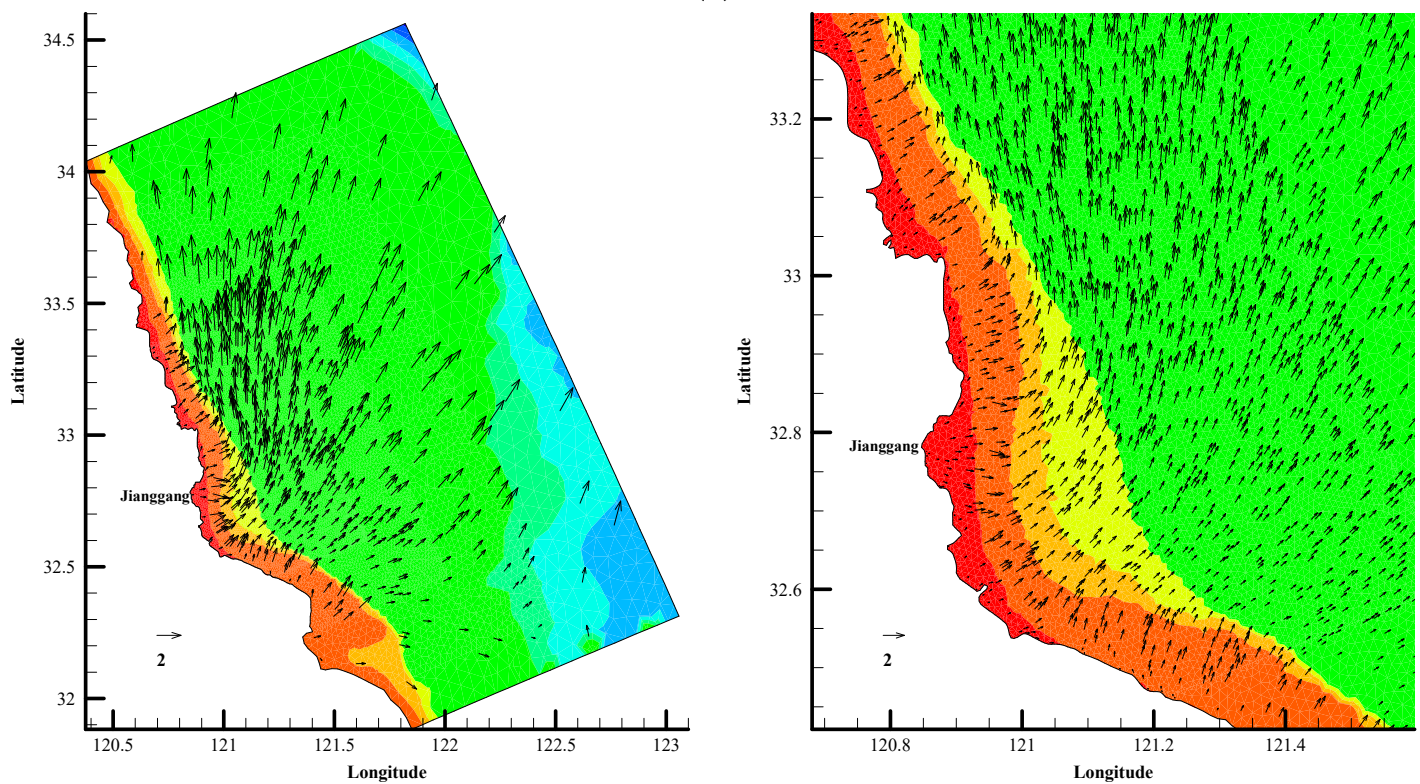

(b)

Figure 8. Maximum flood and ebb current fields when there are no RSRs (the base map shows the topography: left is the global tidal current field and right is the local tidal current field); (a) Maximum flood; (b) Maximum ebb.

As shown in the local tidal current field, the topographic changes do not alter the distribution pattern of the radial tidal current field but affect local current fields. Compared to natural RSRs and partially reclaimed RSRs, in the case of no RSRs, the tidal current can go directly to Jianggang and the flow rate is approximately $0.7-0.9 \mathrm{~m} / \mathrm{s}$ near the shore of Jianggang. 

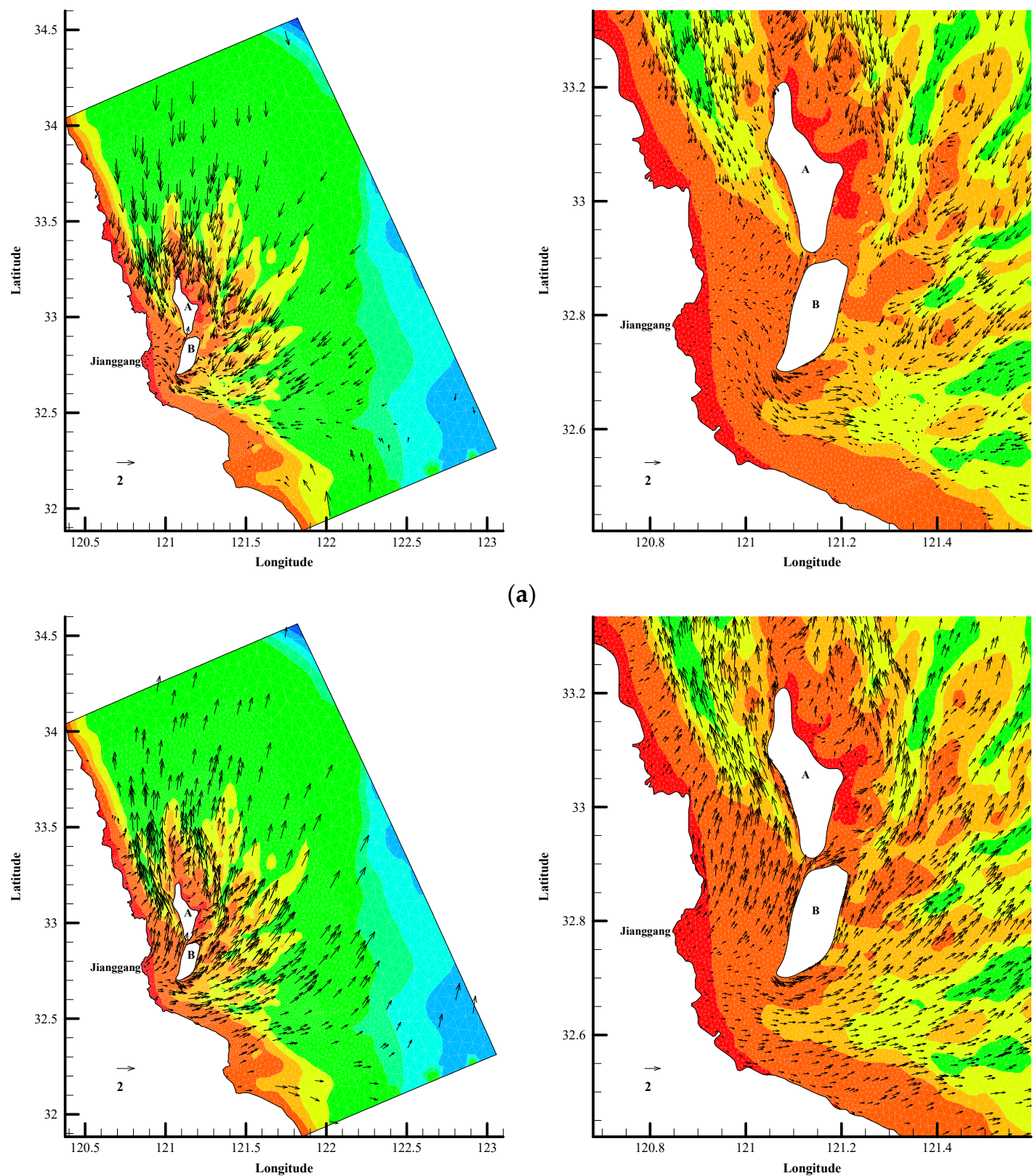

(a)

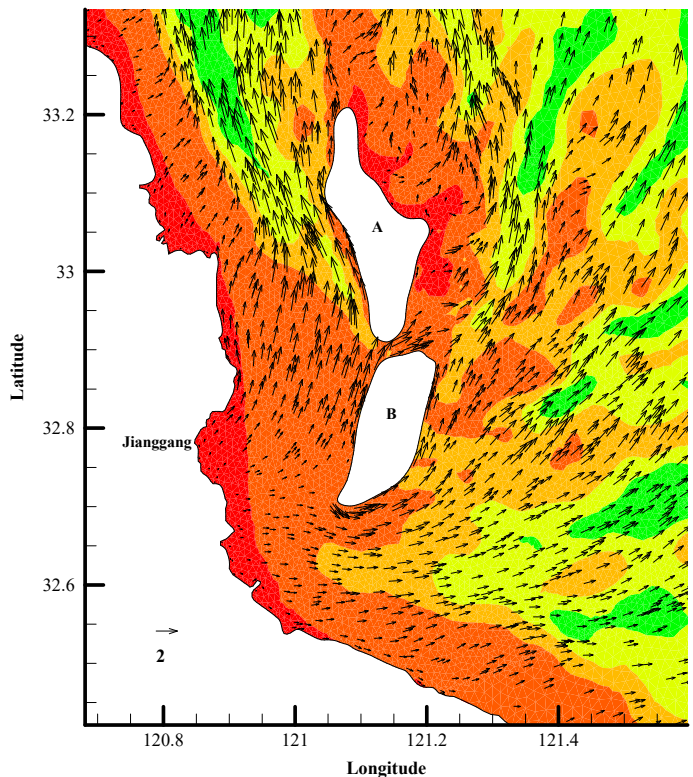

(b)

Figure 9. Maximum flood and ebb current fields when the RSRs are partially reclaimed (the base map shows the topography: left is the global tidal current field and right is the local tidal current field); (a) Maximum flood; (b) Maximum ebb.

\subsection{Analysis of the Response of the Tidal Current Field to the RSRs}

To further analyse the response of the tidal current field to the morphology of RSRs, tidal current streamlines were plotted for the three designed scenarios, i.e., natural RSRs, no RSRs and partially reclaimed RSRs. Figure 10 shows the global tidal current streamlines and Figure 11 shows the local tidal current streamlines.

As shown in Figure 10, the maximum flood and ebb streamlines more clearly show that the tidal current field in the RSR area is in a radial pattern, regardless of whether there are RSRs. The tidal currents converge and diverge at Jianggang during a flood tide and an ebb tide, respectively. The radial tidal current field in the RSR area is stable and is not controlled by the morphology of the RSRs.

The topographic changes do not alter the distribution pattern of the radial tidal current field but affect local current fields. As shown in Figure 11, when there are no RSRs, flood currents can directly 
reach Jianggang. However, under natural RSR condition, the RSRs block the tidal currents during a flood tide. When the tidal currents are unable to overflow the banks during a low tide, they can reach Jianggang only via the deep inlets. This phenomenon is particularly pronounced when the RSRs are partially reclaimed. During an ebb tide, when the tidal currents encounter sand ridges or reclamation areas, their streamlines bend, and they flow around the obstacles. This change will affect the material transport, sediment deposition and seabed erosion. For example, the incident flow surface of a reclamation area blocks the water flow, resulting in a local decrease in the flood and ebb current velocities and, thus, sediment deposition. By contrast, the tidal currents are able to flow by the two sides of this reclamation area without hindrance at an increased velocity and, thus, may erode the original sand ridge, thereby exerting a profound, cumulative impact on the morphology of the RSRs.
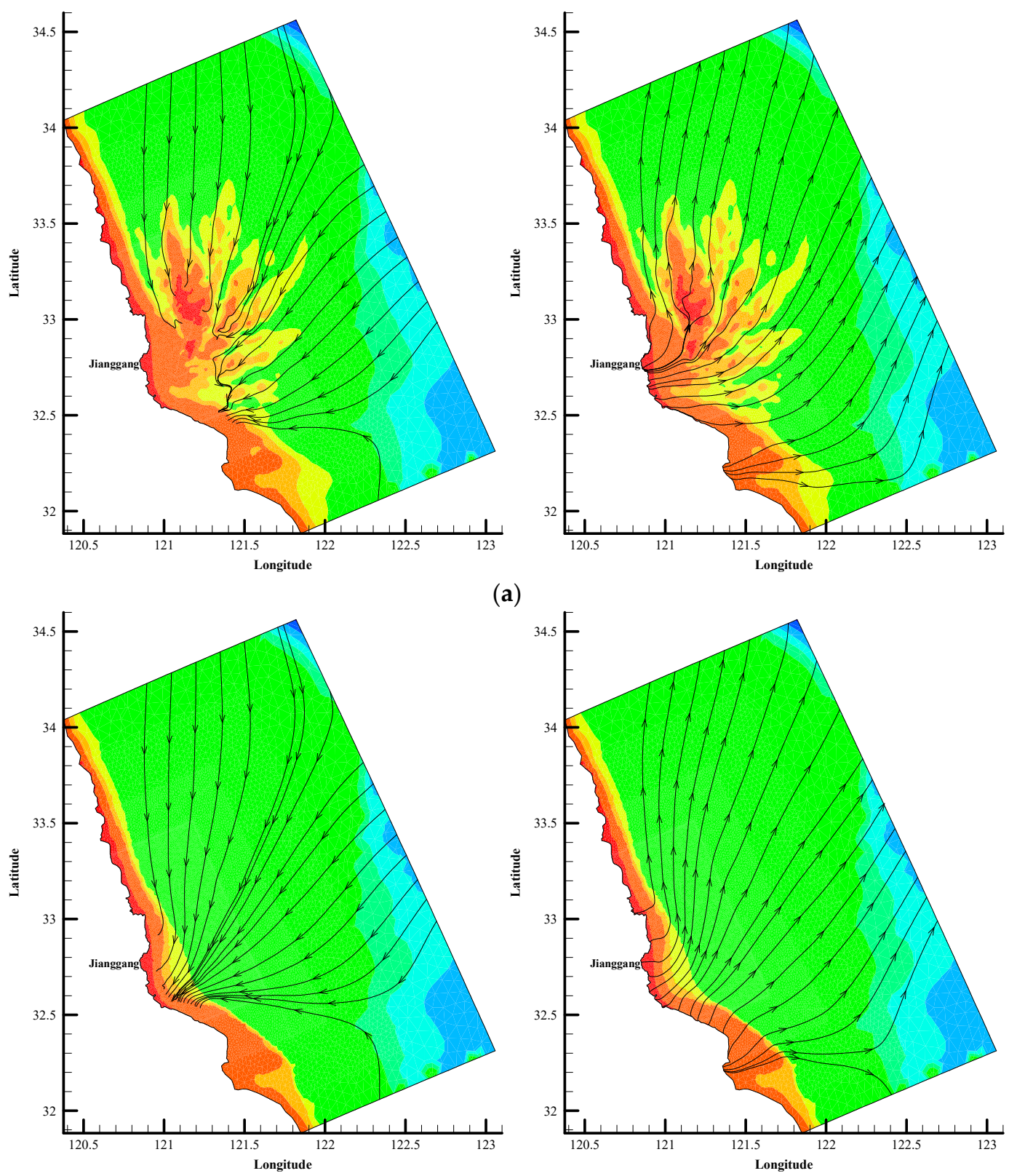

(a)

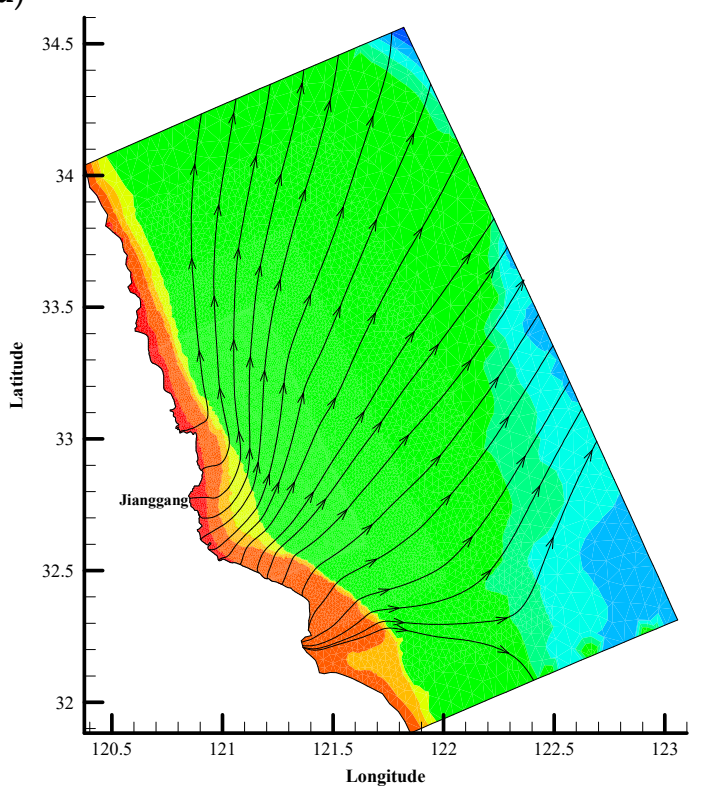

(b)

Figure 10. Cont. 

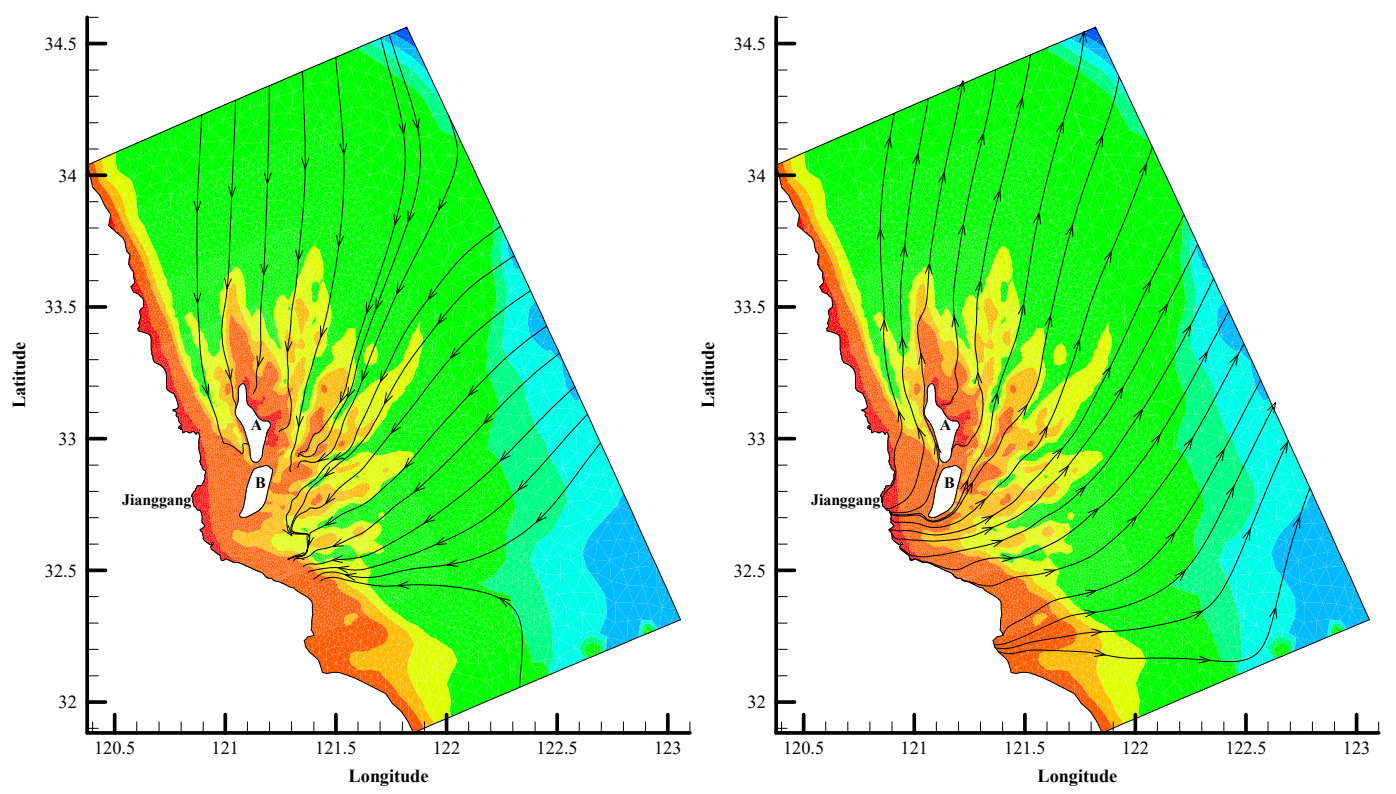

(c)

Figure 10. The tidal current streamlines in different topographic conditions (the base map shows the topography); (a) Maximum flood and ebb streamlines when the natural RSRs are present; (b) Maximum flood and ebb streamlines when there are no RSRs; (c) Maximum flood and ebb streamlines when the RSRs are partially reclaimed.
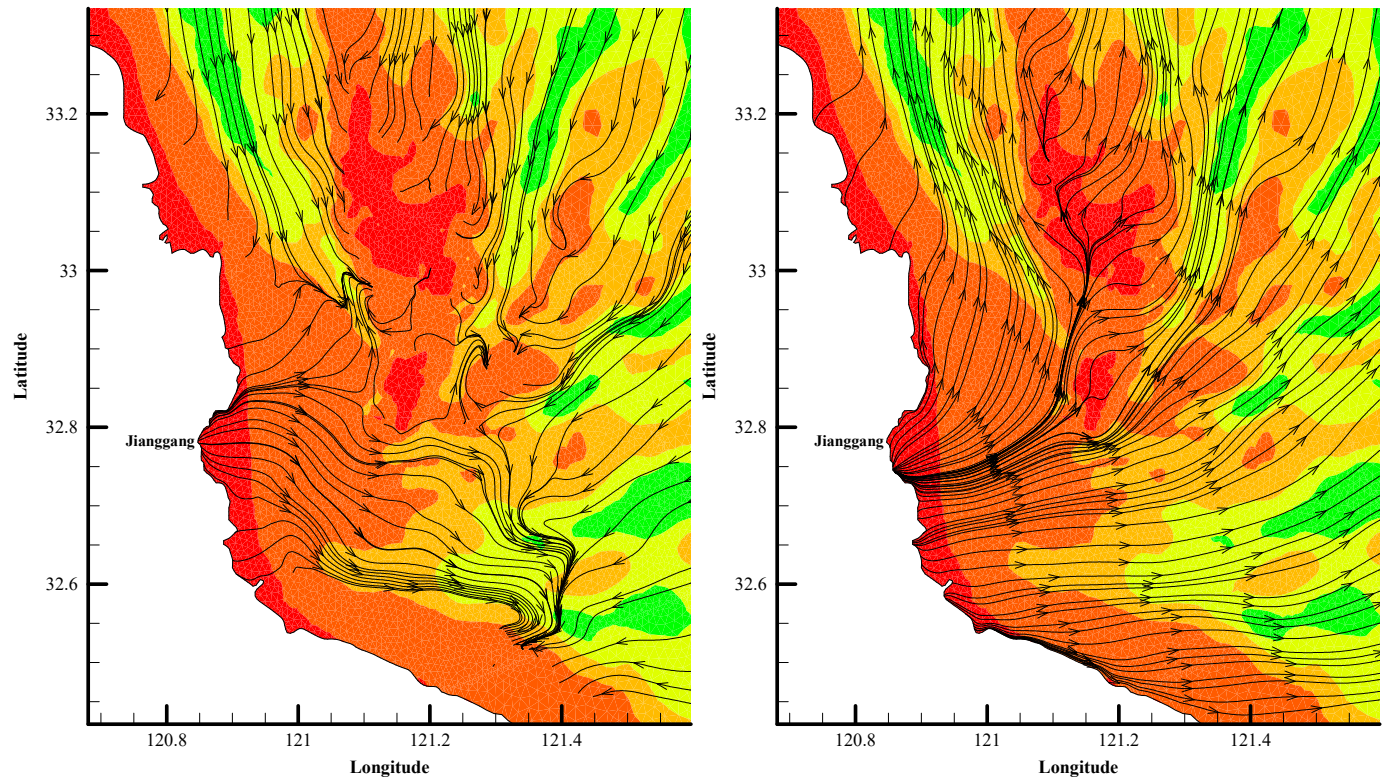

(a)

Figure 11. Cont. 

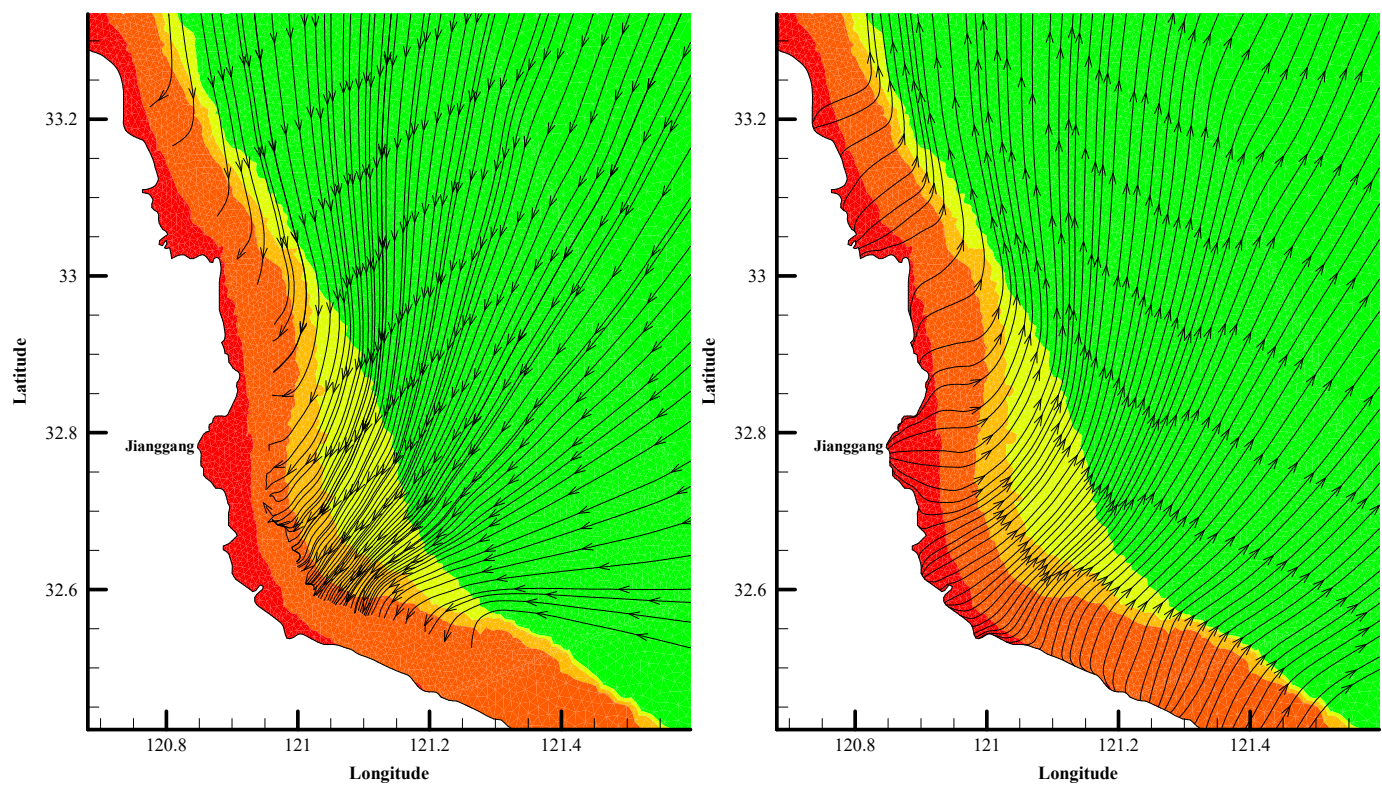

(b)
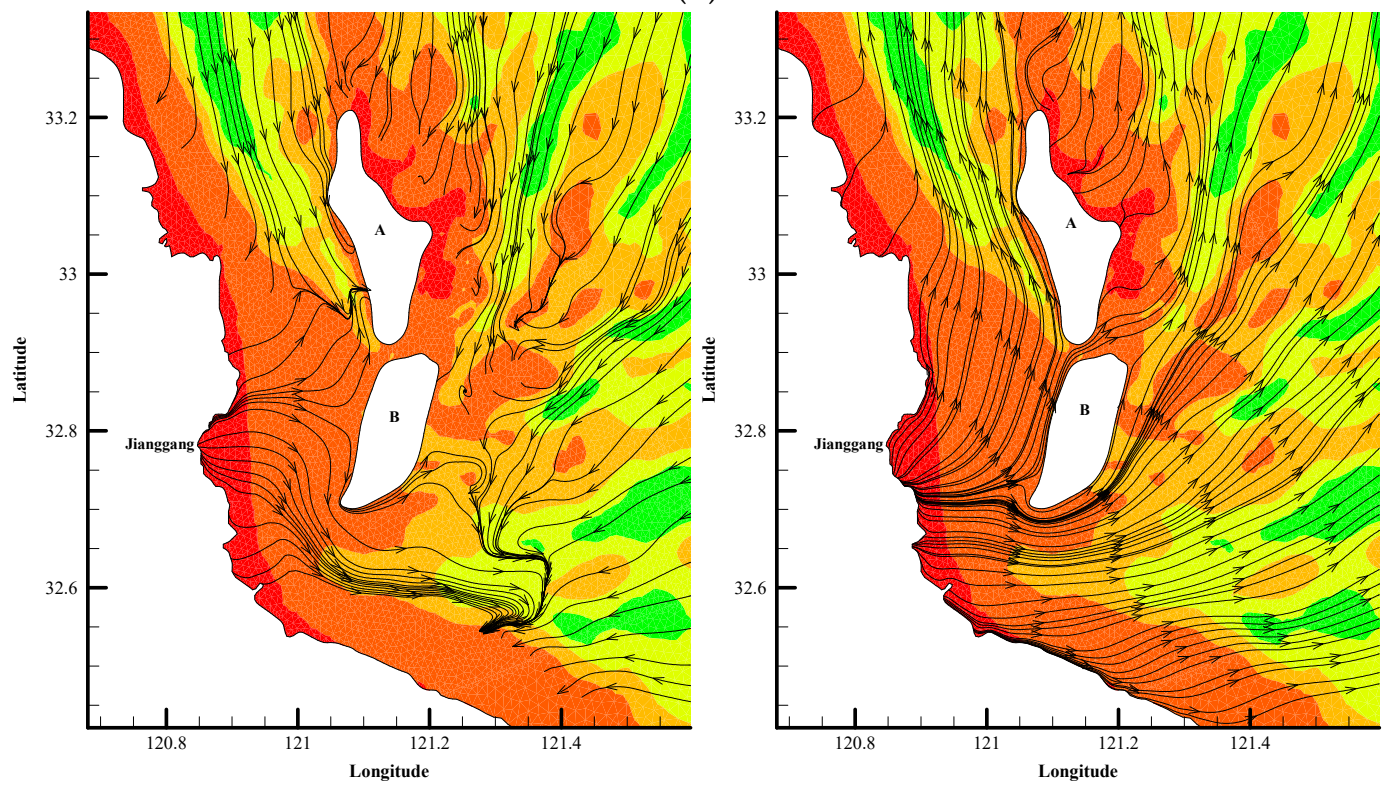

(c)

Figure 11. The tidal current streamlines in the local area (the base map shows the topography); (a) Maximum flood and ebb streamlines when the natural RSRs are present; (b) Maximum flood and ebb streamlines when there are no RSRs; (c) Maximum flood and ebb streamlines when the RSRs are partially reclaimed.

\section{Discussion}

Through simulation, it was found that the radial tidal current field in the RSR area is stable and is not controlled by the morphology of the RSRs and that topographic changes do not alter the distribution pattern of the radial tidal current field. Therefore, the tidal action plays an important role in the formation of the submarine sand ridges.

Some studies have also shown that the trend plays an important role in sand ridge shaping. Davis et al. conducted a detailed investigation of linear sand ridges off the southwest coast of Florida, United States and found that they are tide-dominated sand bodies and that tidal currents play a significant role in the sediment distribution [35]. Asymmetric tidal currents provide a hydrodynamic basis for sand sources of linear sand ridges [36-38]. In addition, waves also play a role in the formation of sand 
ridges that cannot be overlooked. For example, in the Celtic Sea, intense erosion by waves and tidal waves resulted in the formation of shore-oblique ridges [39].

The topographic changes do not alter the distribution pattern of the radial tidal current field but affect local current fields. Five points were selected to analyse the local flow rate changes under different terrain conditions. The position of the points are shown in Figure 12 and the flow rate change values are shown in Table 5.

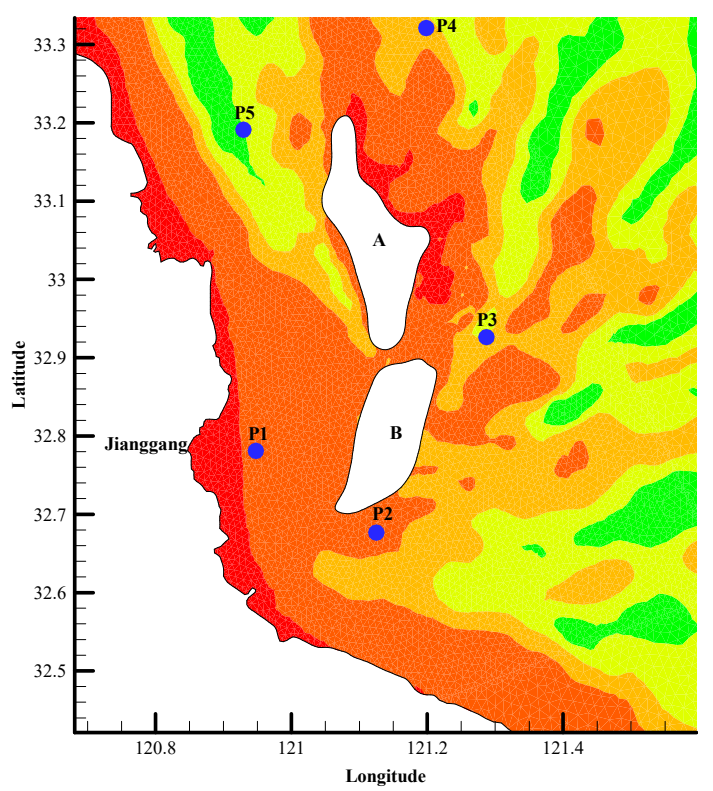

Figure 12. The position of the flow rate analysis points.

Table 5. Flow rate change value $(\mathrm{m} / \mathrm{s})$.

\begin{tabular}{ccccccc}
\hline \multirow{2}{*}{ Point } & \multicolumn{2}{c}{ Natural RSRs } & \multicolumn{2}{c}{ No RSRs } & \multicolumn{2}{c}{ Partially Reclaimed RSRs } \\
\cline { 2 - 7 } & $\begin{array}{c}\text { Maximum } \\
\text { Ebb }\end{array}$ & $\begin{array}{c}\text { Maximum } \\
\text { Flood }\end{array}$ & $\begin{array}{c}\text { Maximum } \\
\text { Ebb }\end{array}$ & $\begin{array}{c}\text { Maximum } \\
\text { Flood }\end{array}$ & $\begin{array}{c}\text { Maximum } \\
\text { Ebb }\end{array}$ & $\begin{array}{c}\text { Maximum } \\
\text { Flood }\end{array}$ \\
\hline P1 & 0.65 & 0.36 & 1.15 & 0.43 & 0.55 & 0.38 \\
P2 & 1.04 & 0.74 & 0.83 & 0.62 & 1.38 & 0.82 \\
P3 & 1.66 & 0.76 & 1.07 & 0.93 & 1.34 & 0.66 \\
P4 & 1.50 & 1.85 & 1.65 & 1.60 & 1.40 & 1.81 \\
P5 & 2.29 & 1.39 & 1.34 & 1.45 & 2.08 & 1.40 \\
\hline
\end{tabular}

P1 is located near the shore. Compared with natural RSRs, the maximum ebb flow rate of no RSRs increased by $77.5 \%$. The maximum flood flow rate increase is $21.0 \%$. P2 is located on the south side of the B-area. The flow rate of the partially reclaimed RSRs is greater than the flow rate of the natural RSRs and no RSRs. The main reason is that the flow around the reclamation area and the flow velocity at the P2 point increased. P3 and P4 are located on the east side of the reclamation area. Compared with the natural RSRs, the maximum ebb flow rate of the partially reclaimed RSRs at P3 and P4 decreased by $19.1 \%$ and $7.1 \%$, respectively, and the maximum flood flow rate decreased by $12.8 \%$ and $2.2 \%$, respectively. P5 is located at the Xiyang tidal inlet. Under the conditions of natural RSRs and partially reclaimed RSRs, the maximum ebb flow rate exceeds $2 \mathrm{~m} / \mathrm{s}$. Under the no RSR condition, the maximum ebb flow rate reduced by approximately $40.0 \%$.

This study was conducted from the perspective of the relationship between the morphology of RSRs and the hydrodynamic environment in the coastal waters. In addition, in this study, the response of the hydrodynamic environment to the morphology of RSRs was simulated under given tidal current boundary conditions. Under practical conditions, the tidal currents, waves and sediment transport in the study area are complex processes that affect each another. Moreover, human activity, 
climate change, sea-level rises and storm tides also affect the study area. All these factors increase the uncertainty in the results of this study.

\section{Conclusions}

In this study, a 2D numerical model was set up and verified with 5 tide level observation points and 7 tidal current observation points in the study area. To study the response of the hydrodynamic environment to the morphology of RSRs, three topographic conditions were calculated in the hydrodynamic model, namely, natural RSRs, no RSRs and partially reclaimed RSRs. Conclusions can be drawn as follows:

(1) The tidal current is the main driving force for the formation and development of radiant sandbars and plays an important role in the formation of sand ridges.

(2) The timing of the formation of radiant sandbars is different and the previous research results have been shown to be mostly in the order of thousands of years.

(3) When simulating the tidal field under three different terrain conditions, the radial tidal field in the radiated sandbar area is stable and is not controlled by the radiant sandbar form.

(4) The topographical change does not change the distribution pattern of the radial tidal field, but it will have a certain impact on the local flow field. Under the conditions of natural RSRs and partially reclaimed RSRs, the streamline bends and flows around the sand ridge or the reclamation area. Due to the topography blocking, the flow rate on the upstream face of the reclamation area decreases and the flow rate on both sides of the reclamation area increases.

Author Contributions: Conceptualization, C.Q.; Methodology, C.Q. and J.L.; Validation, C.Q. and L.M.; Formal Analysis, H.Z.; Investigation, C.Q.; J.L. and H.Z.; Resources, C.Q.; Data Curation, C.Q. and Y.Z.; Writing-Original Draft Preparation, C.Q.; Writing-Review \& Editing, L.M.; J.L. and Y.Z.; Supervision, L.M. and Q.W.; Project Administration, C.Q.; Funding Acquisition, L.M. and Q.W.

Funding: This work was financially supported by the Project of the National Key Research and Development Program of China (2016YFC0401504).

Conflicts of Interest: The authors declare no conflicts of interest.

\section{References}

1. Li, M. Progress of research and development of radial sand ridges. J. Waterw. Harb. 2011, 32, $229-243$.

2. Off, T. Rhythmic linear sand bodies caused by tidal currents. Am. Assoc. Pet. Geol. Bull. 1963, 43, 324-327.

3. Xia, D.; Liu, Z. The submarine sand ridges in China waters. J. Oceanogr. Huanghai Bohai Seas 1983, 1, 45-56.

4. Liu, Z.; Xia, D. A preliminary study of tidal current ridges. Oceanol. Limnol. Sin. 1983, 14, 286-296.

5. Cheng, J.; Gao, S.; Wang, Y.; Min, F. Grain size characteristics of surficial sediments and their response to hydrodynamics over the coastal waters of northern Jiangsu Province. Mar. Geol. Quat. Geol. 2009, 29, 7-12. [CrossRef]

6. Xia, D.; Liu, Z. Formation mechanism and development conditions of tidal current ridges. Acta Oceanol. Sin. 1984, 6, 361-367.

7. Zhu, Y.; Chang, R. Explanation of the cause of formation of radial sand ridges in the southern Yellow Sea through numerical simulation of tidal currents. J. Ocean Univ. Qingdao 1997, 2, 90-96.

8. Zhang, D.; Junlun Zhang, J.; Zhang, C.; Wang, Z. Creation of tidal currents-destruction by storms-restoration of tidal currents-A preliminary explanation for the dynamic mechanism of formation and evolution of the submarine radial sand ridge group in the Yellow Sea. Sci. China 1998, 5, 394-402.

9. Zhu, Y.; Yan, Y.; Xue, H. A study on the hydrodynamic mechanism of formation and development of radial sand ridges in the southern Yellow Sea-I. Planar characteristics of tidal current movement. Sci. China 1998, 5, 403-410.

10. Song, Z.; Yan, Y.; Xue, H.; Mao, L. A study on the hydrodynamic mechanism of formation and development of radial sand ridges in the southern Yellow Sea-II. Sectional characteristics of tidal current movement. Sci. China 1998, 5, 411-417. 
11. Zhu, Y.; Chang, R. Sediment dynamics study on the origin of the radial sand ridges in the southern Yellow Sea. Studia Mar. Sin. 2001, 43, 38-50.

12. Huang, Y.; Wang, W. A study on the dynamic mechanism of the radial sand ridge group off the coast of Jiangsu. Acta Oceanol. Sin. 1987, 9, 209-215.

13. Liu, Z.; Berné, S.; Saito, Y.; Yu, H.; Trentesaux, A.; Uehara, K.; Wang, X. Internal architecture and mobility of tidal sand ridges in the East China Sea. Cont. Shelf Res. 2007, 27, 1820-1834. [CrossRef]

14. Yang, C. A study on the cause of formation of radial sand ridges off the coast of Jianggang. Mar. Geol. Quat. Geol. 1985, 3, 35-44.

15. Zhang, G.W. Formation and evolution of sand ridges in the south Huanghai Sea Shelf. Mar. Geol. Quat. Geol. 1991, 11, 25-35.

16. Qian, X.; Chen, Y.; Zhang, C.; Pan, Y.; Das, H. Radial tidal current field in a semi-enclosed rectangular basin: formation and evolution. Chin. J. Oceanol. Limnol. 2015, 33, 1085-1099. [CrossRef]

17. Li, C.; Wang, J.; Li, P. A preliminary study on the sedimentary facies of the Yangtze River Delta. J. Tongji Univ. 1979, 2, 1-14.

18. Yang, C.S. On the origin of Jianggang radial sand ridges in Yellow Sea. Mar. Geol. Quat. Geol. 1985, 5, 35-44.

19. Li, C.; Li, B. A study on the cause of formation of ocean banks along the northern coast of Jiangsu. Oceanol. Limnol. Sin. 1981, 4, 321-331.

20. Zhou, C.; Sun, J. Discussion on the cause of formation of shoals off the northern coast of Jiangsu. Mar. Geol. Res. 1981, 1, 83-91.

21. Li, M.; Yang, S.; Han, X. On hydro-dynamic sediment problems in the development of deepwater port in radial sandbanks. Port Waterw. Eng. 2011, 4, 1-8.

22. Zhang, C.; Zheng, J.; Liu, G.; Huang, H. Characteristics of hydrodynamics in the coastal waters of Jiangsu and its response to reclamation projects. J. Econ. Water Resour. 2012, 30, 6-9.

23. Zhang, C.; Chen, X. Offshore environmental changes and countermeasures in response to large-scale tidal flat reclamation. J. Hohai Univ. 2015, 43, 424-430.

24. Li, M.; Shi, Z. Numerical modeling study of tidal flow for construction of an artificial island on Xitaiyangsha Shoal at Rudong, Jiangsu Province. China Harb. Eng. 2006, 3, 1-4.

25. Chen, K.; Lu, P.; Wang, Y. Influence of construction of artificial island in Rudong, Jiangsu upon hydrodynamics, erosion and siltation in surrounding water areas. China Harb. Eng. 2008, 1, 8-12.

26. Guo, L.; Yang, S. Influence of artificial island construction on hydrodynamics in waters around Rudong. J. Waterw. Harb. 2009, 30, 342-346.

27. Qi, C.; Liao, Q.; Dong, H.; Yang, J.; Li, J. Analysis of the effects of the wind power plant in the intertidal zone in the offshore radial sand ridge area of Jiangsu on the marine hydrodynamic field. Environ. Pollut. Control 2011, 33, 69-74.

28. Xing, F.; Wang, Y.P.; Wang, H.V. Tidal hydrodynamics and fine-grained sediment transport on the radial sand ridge system in the southern Yellow Sea. Mar. Geol. 2012, 291, 192-210.

29. Chen, J.; Zhang, R. Remote sensing of radiate sandbanks dynamics in Jiangsu (China). Mar. Sci. 2004, 28, 77-80.

30. Chen, L.; Zhang, Y. Analysis of the evolution on tidal flat and their reasons in Dongsha based on remote sensing. In Proceedings of the 2011 IEEE International Conference on Spatial Data Mining and Geographical Knowledge Services, Fuzhou, China, 29 June-1 July 2011; pp. 557-561.

31. Qi, C.; Wu, W.; Jiang, X.; Wang, Q. Numerical simulation of the impact for offshore wind farm on marine hydrodynamic filed in Xiangshui of Jiangsu. China Harb. Eng. 2014, 4, 6-9.

32. Tao, J.; Zhang, C.; Yao, J. Effect of large-scale reclamation of tidal flats on tides and tidal currents in offshore areas of Jiangsu Province. J. Hohai Univ. 2011, 39, 225-230.

33. Tao, J.; Zhang, C. Numerical simulation of water environment for radial sandy ridge area of the Yellow Sea. J. Hohai Univ. 2005, 4, 472-475.

34. Martyr-Koller, R.C.; Kernkamp HW, J.; van Dam, A.; van der Wegen, M.; Lucas, L.V.; Knowles, N.; Fregoso, T.A. Application of an unstructured 3D finite volume numerical model to flows and salinity dynamics in the San Francisco Bay-Delta. Estuar. Coast. Shelf Sci. 2017, 192, 86-107. [CrossRef]

35. Richard, A.; Davis, J.K.; Pliny, J. Sedimentology and stratigraphy of tidal sand ridges Southwest Florida inner shelf. J. Sediment. Res. 1993, 63, 91-104. 
36. Huthnance, J.M. On one mechanism forming linear sand banks. Estuar. Coast. Shelf Sci. 1982, 14, 79-99. [CrossRef]

37. Huthnance, J.M. Tidal current asymmetries over the Norfolk Sandbanks. Estuar. Coast. Mar. Sci. 1973, 1, 89-99. [CrossRef]

38. Caston, V.N.D. Linear sand banks in the southern North Sea. Sedimentology 1972, 18, 63-78. [CrossRef]

39. Berne, S.; Lericolais, G.; Marsset, T.; Bourillet, J.F.; De Batist, M. Erosional offshore sand ridges and lowstand shorefaces; examples from tide- and wave-dominated environments of France. J. Sediment. Res. 1998, 68, 540-555. [CrossRef]

(C) 2019 by the authors. Licensee MDPI, Basel, Switzerland. This article is an open access article distributed under the terms and conditions of the Creative Commons Attribution (CC BY) license (http://creativecommons.org/licenses/by/4.0/). 